\title{
The potential effect of bepridil on vasospastic angina in atrial fibrillation patients undergoing catheter ablation
}

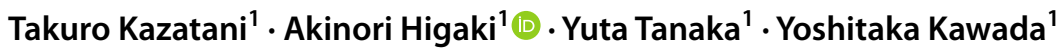 \\ Received: 21 February 2022 / Accepted: 24 February 2022 \\ (c) The Author(s), under exclusive licence to Springer Science+Business Media, LLC, part of Springer Nature 2022
}

\section{To the Editor,}

We read with great interest the article by Hachisuka, reporting the characteristics of coronary artery spasms in patients undergoing catheter ablation of atrial fibrillation (AF)[1]. It was interesting that the patients with coronary artery spasm had a higher frequency of smoking habit, smaller left atrial diameter, and lower CHADS2 score, while no significant difference was observed between groups in the beta-blocker and calcium channel blocker (CCB) use. As CCBs are the first-line therapy for vasospastic angina, it is conceivable that a certain amount of perioperative vasospasm can be masked by CCB medication. However, this point is not sufficiently discussed in the article. The pharmacology of CCBs is characterized by their combined effects on arrhythmia, hypertension, and angina pectoris, but the strength of each effect varies from drug to drug [2]. Among the CCBs, bepridil hydrochloride is particularly notable for its antiarrhythmic effects. Bepridil is recommended as the standard antiarrhythmic drug for rhythm control in persistent AF in the Japanese pharmacotherapy guidelines for AF [3]. Since about $30 \%$ of the patients included in the study had nonparoxysmal atrial fibrillation, it is expected that some number of patients were taking bepridil. The efficacy of bepridil in chronic coronary syndrome has been reported in the past [4], but the extent of its effect on coronary spasm is still undetermined. Therefore, we are very interested in the type of CCB (especially whether it was bepridil or not) that the patients with perioperative coronary spasm were taking in this study. We believe such information can lead to the better outcome of catheter ablation for AF.

\section{Declarations}

Ethics approval The ethical committee of Ehime Prefectural Central Hospital approved submitting this letter.

Consent to participate Not applicable.

Conflict of interest The authors declare no competing interests.

\section{References}

1. Hachisuka M, et al. Perioperative coronary artery spasms in patients undergoing catheter ablation of atrial fibrillation. $\mathrm{J}$ Interv Card Electrophysiol. 2021. https://doi.org/10.1007/ s10840-021-01089-6.

2. Godfraind T. Calcium channel blockers in cardiovascular pharmacotherapy. J Cardiovasc Pharmacol Ther. 2014;19:501-15.

3. Guidelines for Pharmacotherapy of Atrial Fibrillation (JCS 2013). Circ. J. 78, 1997-2021 (2014).

4. Weiss RJ, et al. Efficacy and safety of bepridil in chronic stable angina pectoris refractory to nifedipine. Am $J$ Ther. 1994;1:276-80.

Publisher's note Springer Nature remains neutral with regard to jurisdictional claims in published maps and institutional affiliations.
Akinori Higaki

keroplant83@gmail.com

1 Department of Cardiology, Ehime Prefectural Central Hospital, 83, Kasuga-machi, Matsuyama, Matsuyama, Ehime 790-0024, Japan 